\title{
OPTIMALISASI PRODUKTIFITAS DAN KINERJA ALAT BERAT DENGAN ANALISA DATA REAL TIME PARAMETER
}

\author{
Nova Budi Satriawan \\ Senior Engineer Mechanical, Maintenance System, Mining Support Division, \\ PT.Kaltim Prima Coal
}

\begin{abstract}
ABSTRAK
Alat berat, kendaraan berukuran besar, yang didesain khusus untuk mendukung operasional penambangan, adalah salah satu aset vital di perusahaan tambang. Alat berat memiliki penggerak bertenaga besar dan kebanyakan sudah dilengkapi sistem kontrol electronic dengan teknologi yang canggih oleh pabrikan pembuat alat berat. Di era Industri 4.0, perkembangan teknologi informasi sangat pesat, transformasi digital memungkinkan penyajian data secara real time dengan lebih cepat, dalam kapasitas jumlah data yang sangat besar (big data) dan biaya yang relatif murah. Selain itu, dengan adanya virtual coud database dan perkembangan software data scienctist dan data analyst, integrasi dan pengolahan data dari berbagai database dapat dilakukan secara otomatis. Analisa data bahkan sampai pelaporan dengan berbagai format tampilan sesuai kebutuhan menjadi hal yang sangat mudah untuk dilakukan. Pada alat berat di sektor pertambangan, perkembangan teknologi ini ini dapat dimanfaatkan untuk improvement baik di sisi production maupun maintenance, dengan mengkustomisasi dan mengkombinasikan data real time parameter untuk memonitor produktifitas, konsumsi bahan bakar, kondisi kesehatan unit, bahkan sampai perilaku operator dan kondisi jalan tambang. Bahan bakar dan ban adalah biaya konsumsi yang sangat besar dalam pengoperasian tambang, dengan dapat dikontrolnya dua item tsb menjadi efektif dan efisien, serta dengan meningkatnya produkitivitas dan kinerja alat berat, maka keuntungan perusahaan akan meningkat.
\end{abstract}

Kata Kunci : data scienctist, data analyst, kondisi kesehatan unit, perilaku operator, kondisi jalan tambang

\begin{abstract}
Heavy Equipments, are huge vehicle that designed spesificly for support mining operation, it is one of the vital assets in mining company. Heavy Equipment has high torque engine, most of its are already equiped with sophisticated electronic control system by original equipment manufacturer. Nowadays, in industry 4.0 age, information technology growing very fast, digital transformation allows real time big data transmitting and display much more quickly and cheaper than before. And also, by the existence of virtual cloud database storage and many development in data scientist and data analyst software, data integration and analysis are now can be done automatically. Analysis and Reporting with customize telmpate as needed are easy to be done. In mining heavy equipment, this technology development can be used for improvement in both side production and maintenance, by customize and combine real time parameter data to monitor productivity, fuel consumtion, equipment health condition, and also operator abuse behaviour and haul road condition. Fuel and are tyrethe mostexpensive consumable expense in mining operation, by controlling these two items to be more efective and efficient, and also with the increasing of productivity and equipment performance, the profit of company will be increase.
\end{abstract}

Key Words : data scienctist, data analys, equipment health condition, operator abuse behaviou, haul road condition 


\section{A. PENDAHULUAN}

Alat berat memegang peranan penting di Perusahaan Tambang, ketersedian dan kehandalannya sangat dibutuhkan untuk mendukung operasional pertambangan. Ukuran dan kapasitas produksi serta energi dan biaya untuk pengoperasiannya yang sangat besar, menjadikan pemantauan produktifitas dan kinerjanya agar selalu sesuai dengan target perusahaan menjadi suatu kebutuhan yang logis dan sangat penting

Berbagai macam tipe aplikasi alat berat digunakan sesuai kebutuhan dan proses penambangan, mulai dari Digger, Hauling Equipment, Dozer, Grader, Drill, Pump, Lighting Tower, Genset dll. Alat-alat berat ini, dari bawaan asal pabrikan pembuatnya, kebanyakan sudah dilengkapi dengan teknologi yang cukup canggih, yaitu electronic control system. Teknologi ini dipasang di unit untuk memudahkan end user atau customer dalam penggunan dan pengoperasian serta pemeliharannya.

Electronic control system terdiri dari sensor, jaringan electronic, dan electronic control module $(\mathrm{ECM})$, output dari sistem ini adalah berupa data electronic. Teknologi ini mirip seperti black box di dalam pesawat yang dapat menyimpan semua data electronic berisi informasi kondisi mesin pesawat selama pesawat tersebut beroprasi.

Manajemen data electronic yang baik dibutuhkan untuk mengolah data-data yang diperoleh dari electronic control system menjadi informasi penting yang bermanfaat untuk mengoptimalkan penggunaan alat berat sesuai dengan target dan ekspektasi yang diharapkan perusahaan. Manajemen data electronic terdiri dari pengiriman, penyimpanan, pengolahan data, sampai pelaporan parameter-parameter penting kondisi alat berat.

Tantangan yang dihadapi adalah, data electronic yang dihasilkan oleh ECM masih tersimpan di media penyimpanan di dalam unit tersebut, dibutuhkan suatu proses akuisisi / pengambilan data agar data tersebut dapat dimanfaatkan. Pengambilan data masih harus dilakukan dengan download secara manual, bahkan beberapa tipe alat berat masih ada juga yang belum mempunyai electronic control system terutama alat recorder atau penyimpan data, sehingga data-datanya hanya bisa muncul di layar display kabin operator saja. Selain itu, format dan jumlah data electronic yang dapat disimpan di media penyimpanan bawaan pabrikan, masih sangat terbatas, tidak semua data yang dibutuhkan untuk monitoring unit dapat disimpan. Kemudian tantangan lain adalah, data yang dapat didownload tersebut masih terpisah belum terintegrasi dengan data-data pendukung lain yang dibutuhkan untuk menganalisa secara utuh kinerja alat tersebut. Dibutuhkan satu rangkaian proses lagi yaitu integrasi data sebelum data bisa diolah dan dianalisa secara menyeluruh dan dibandingkan terhadap target atau operational context yang diterapkan perusahaan.

Perkembangan Teknologi Informasi di Era Industri 4.0 sangat pesat, banyak sekali produk hardware dan software yang telah dikembangkan untuk dapat menyajikan data electronis secara langsung (real time) dengan lebih cepat. Data electronic yang dapat di sajikan pun mengalami perubahan yang sangat signifikan, jika sebelumnya pengiriman data umumnya hanya dalam bentuk text atau bahkan masih kode-kode digital binary code yang ukuran filenya kecil, saat ini dengan adanya transformasi digital, maka proses transfer dan transmit data electronic dapat dilakukan dalam jumlah kapasitas yang sangat besar (big data) dan meliputi berbagai format file ( audio maupun video) dan dengan biaya yang relatif murah. Selain itu, dengan adanya virtual cloud database sebagai media penyimpanan media electronic yang dapat diakses oleh berbagai pihak dengan mudah, dan perkembangan software-software yang mempunyai fungsi untuk data scienctist dan data analyst, maka integrasi dan pengolahan data electronic dari berbagai database dapat dilakukan secara otomatis dan dari manapun. 
Pada alat berat tambang, semua perkembangan teknologi ini ini dapat dimanfaatkan untuk improvement dalam manajemen data electronic, sehingga semua rangkaian proses mulai dari data akuisisi, sortir dan penyimpanan data, pengolahan dan analisa, bahkan sampai pelaporan dengan berbagai format tampilan sesuai kebutuhan dapat dilakukan dengan mudah dan cepat, sehingga pengambilan keputusan yang tepat sasaran akan dapat dilakukan dengan telah mempertimbangankan berbagai aspek secara menyeluruh.

PT. Kaltim Prima Coal (KPC) adalah tambang batubara terbesar di Indonesia. Tambang ini berlokasi di Sangatta Kutai Timur Kalimantan Timur. Dalam pengoperasiannya KPC mempunyai ratusan unit alat berat dengan berbagai tipe aplikasi, ukuran dan merek. Kepemilikan aset alat berat di KPC bermacam-macam, ada aset yang dibeli dan dirawat sendiri oleh KPC, namun ada juga yang dikelola oleh kontraktor dan diatur dengan kontrak tertentu. Merek dan pabrikan asal pembuat alat berat di KPC bervariasi antara lain Caterpillar, Komatsu, Hitachi. Liebherr dan Volvo, sedangkan untuk merek dari engine yang digunakan sebagai penggerak alat berat antara lain Caterpillar, Komatsu, MTU, Cummins dan Volvo

Peneliti menjadikan KPC sebagai objek penelitian dengan membahas proyek uji coba yang telah dilakukan untuk mengakuisisi data electronic dari alat-alat berat di KPC secara real time menggunakan suatu produk software tambahan. Peneliti juga mengevaluasi dan mengkalkulasi pentingnya integrasi data electronic dengan data-data lain dari berbagai software dan database yang sudah digunakan di KPC untuk peningkatan atau improvement.

\section{B. METODOLOGI PENELITIAN}

Menurut Indrajit RE (2000) dalam bukunya Manajemen Sistem Informasi dan Teknologi Informasi, "Sistem informasi dapat dianalogikan sebagai sebuah permintaan (demand) dari masyarakat industri, dimana kebutuhan akan sarana pengolahan data dan komunikasi yang cepat dan murah (menembus ruang dan waktu), sedangkan teknologi informasi merupakan jawaban dari dunia industri (supply) terhadap permintaan tersebut dalam bentuk penciptaan produk-produk berbau teknologi perangkat keras dan perangkat lunak". Dari situ dapat dijelaskan bahwa sistem informasi merupakan sekelompok komponen yang berhubungan dengan proses penciptaan dan pengaliran informasi, dan teknologi informasi merupakan bagian atau komponen dari sistem informasi.

Sebagian besar alat berat tambang KPC sudah dilengkapi dengan ECM sebagai bagian dari teknologi dan sistem informasi. Sebagai alat bantu utama yang digunakan untuk melakukan proses penambangan, serta nilai aset yang sangat mahal dan memiliki posisi yang sangat strategis, alat berat memang menjadi aset vital perusahaan, dibutuhkan pengaturan strategy yang sangat baik dalam pengoperasian dan pemeliharaan alat berat di KPC oleh Mining Operation Division (MOD) dan Mining Support Division (MSD).

Strategi pemeliharaan alat berat yang tepat ditandai dengan tercapainya Key Performance Indicator (KPI) Maintenance yaitu Physical Availability (PA) dan Mean Time Between Failure (MTBF). Strategi pemeliharaan alat berbagai macam dan tingkatan, yang paling rendah adalah reaktif maintenance dimana pemeliharaan hanya dilakukan pada saat unit sudah mengalami kerusakan, strategi ini memiliki kelemahan yaitu pengguna tidak dapat mengetahui kapan unit akan rusak dan waktu yang dibutuhkan untuk perbaikan biasanya cukup lama karena sumber daya dan parts yang dibutuhkan untuk melakukan perawatan belum disediakan. Tingkatan strategi maintenance yang lebih tinggi adalah preventive, predictive dan proactive maintenance. Preventive maintenance dilakukan dengan melakukan penjadwalan aktivitas pemeliharaan terlebih dahulu sebelum unit mengalami kerusakan, jadwal yang diretapkan bisa berdasarkan umur oli dan juga umur komponen yang terpasang di unit, target umur pakai oli atau umur pakai komponen didaptkan dari informasi supplier oli atau komponen yang dipakai tersebut. Selanjutnya, predictive maintenance, atau sering 
juga disebut Condition Based Maintenance (CBM), pada level ini pihak maintainer sudah bisa memprediksikan kapan akan terjadi kerusakan pada unit berdasarkan analisa terhadap gejala kerusakan yang sudah mulai timbul dari sample data yang diambil secara rutin di setiap interval waktu tertentu, selanjutnya dari informasi terseabut dapat dijadwalkan kapan seharusnya aktivitas pemeliharaan yang tepat akan dilakukan dengan mengunakan PF-Interval Diagram.

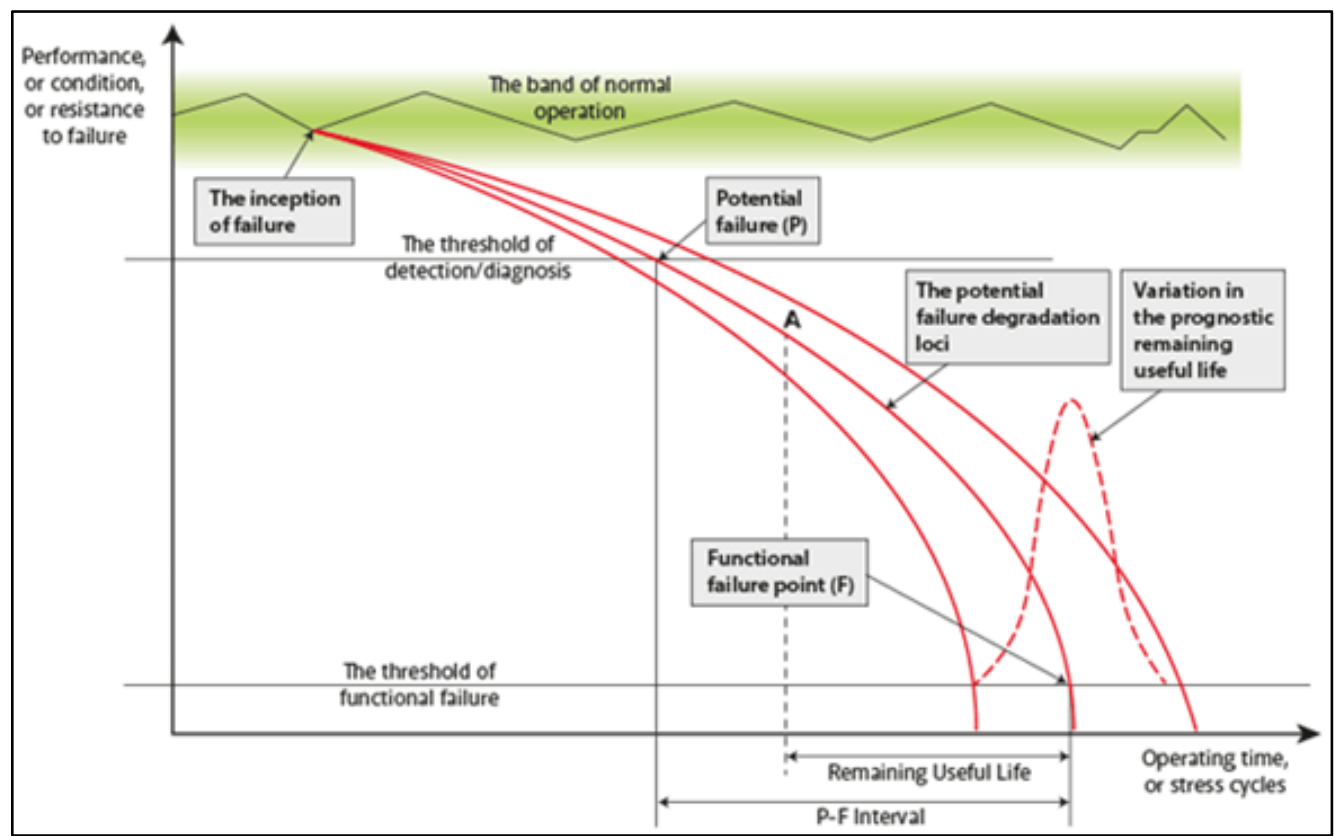

Gambar 1. P-F Interval Diagram

Menurut Jennious Ian (2011) dalam artikelnya The P-F Interval explained, "Untuk dapat memahami skala waktu pada kurva P-F dan tindakan apa yang memungkinkan untuk dilakukan, maka dikenalkan konsep Integrated Vehicle Health Management (IVHM)." Langkah-langkah yang dilakukan dalam konsep IVHM meliputi : Sense - Acquire - Transfer - Analyse - Act. Dimulai dengan pemasangan sensor dan switch untuk mendeteksi critical parameter (level, temperatur, pressure), sampai ke analisa dan melakukan tindakan perbaikan.

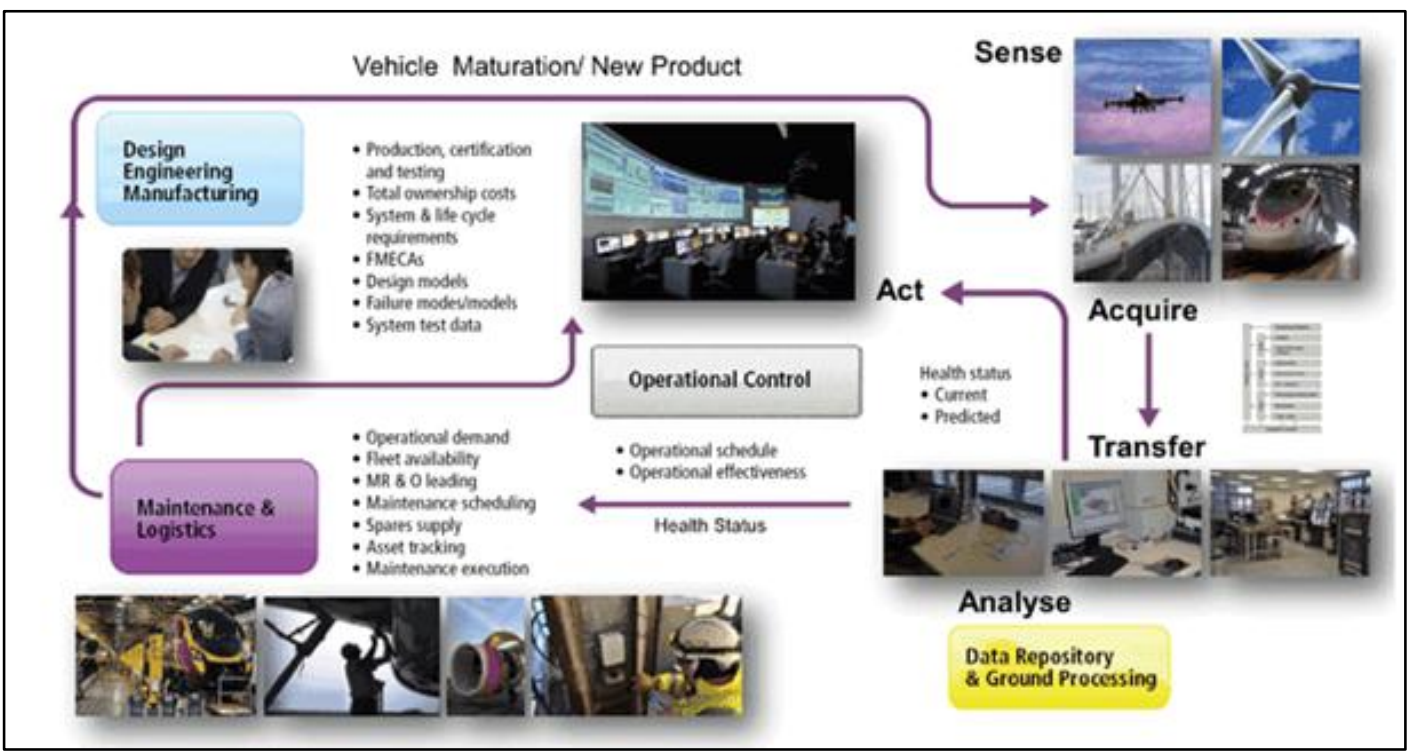

Gambar 2. IVHM Diagram 


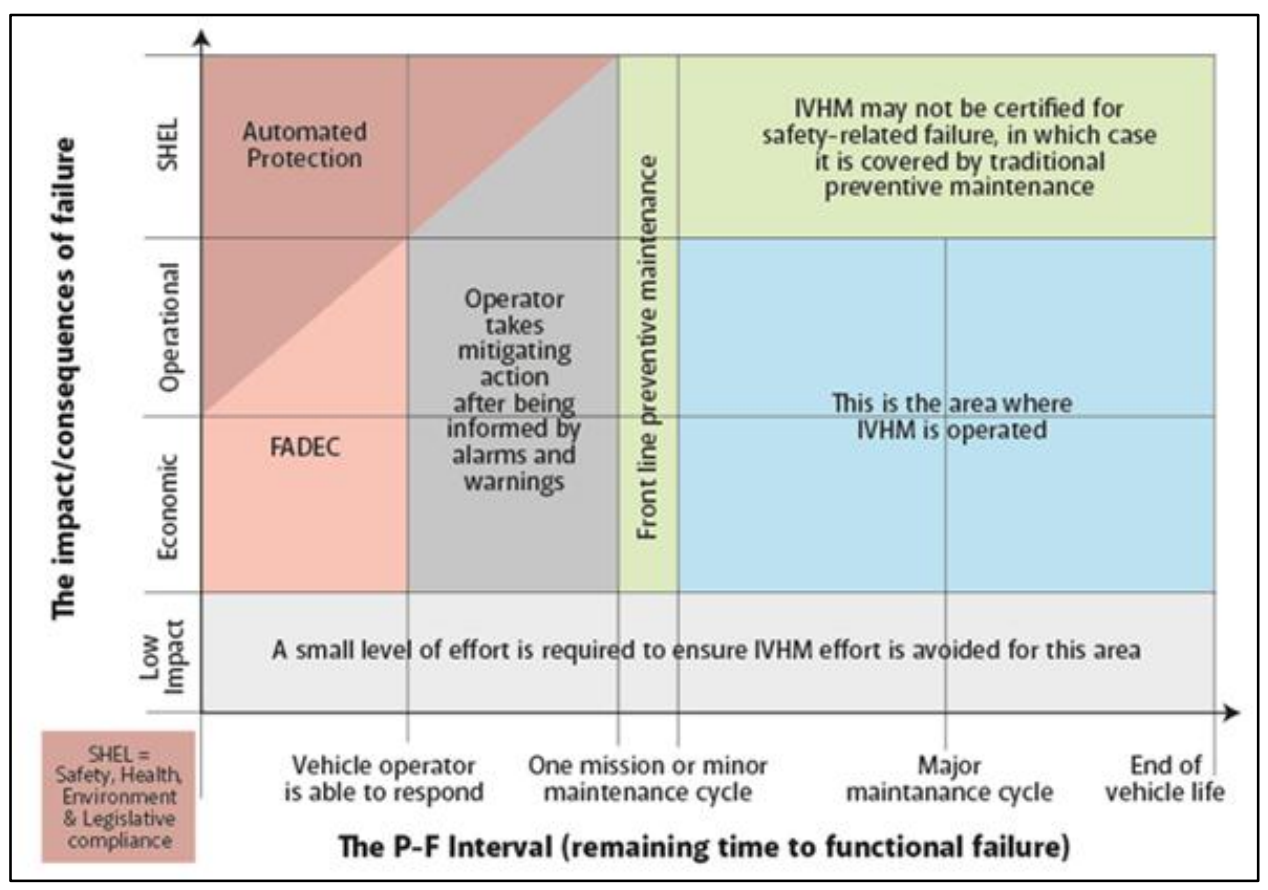

Gambar 3. Impact and Consequences of the P-F Interval

Preventive dan Predictive maintenance lebih efektif karena sumberdaya dan parts sudah bisa disiapkan terlebih dahulu, sehingga durasi perbaikan biasanya menjadi tidak lama. Level selanjutnya, Proactive maintenance, disini sudah dilakukan analisa yang mendalam terhadap akar permasalah problem yang sering terjadi dan dilakukan tindakan-tindakan yang diperlukan untuk menghilangkan akar permasalah tersebut, sehingga tidak terjadi masalah yang berulang, termasuk dalam startegy ini adalah Reliability Centered Maintenance (RCM), Failure Mode and Effect Analysis (FMEA) dan Failure Analysis Report (FAR). Di MSD KPC, semua strategi pemeliharaan tersebut dilakukan sesuai dengan kondisi di lapangan.

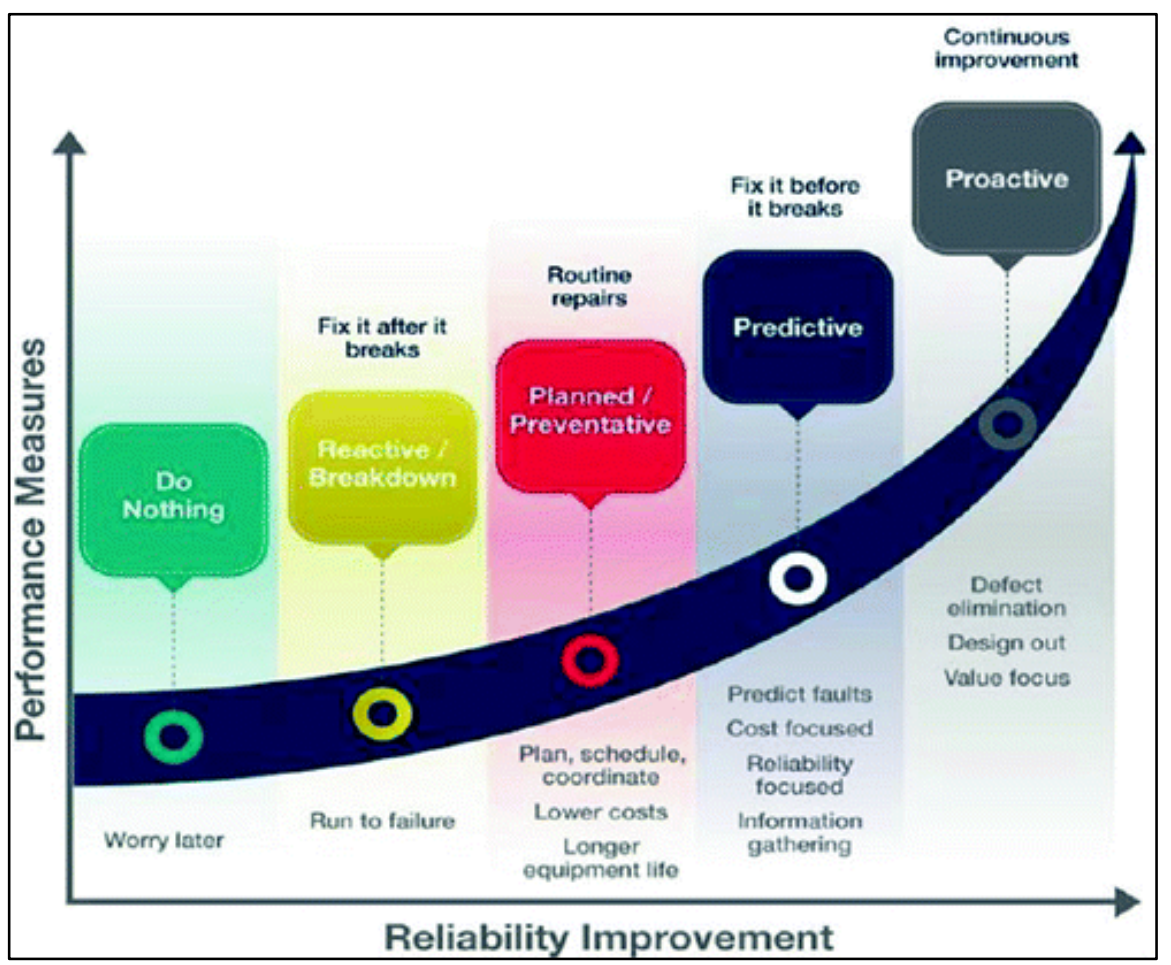

Gambar 4. Evolusi Maintenance Strategy 
Untuk mengatur pekerjaan dan strategi pemeliharaan maka MSD mengatur semua pekerjaan pemeliharaan dalam suatu aturan Work Management yang meliputi semua proses dan langkahlangkah pemeliharaan, yaitu Work Identfication, Work Planning, Work Schedulling, Work Assigment, Work Execution dan Work Closure.

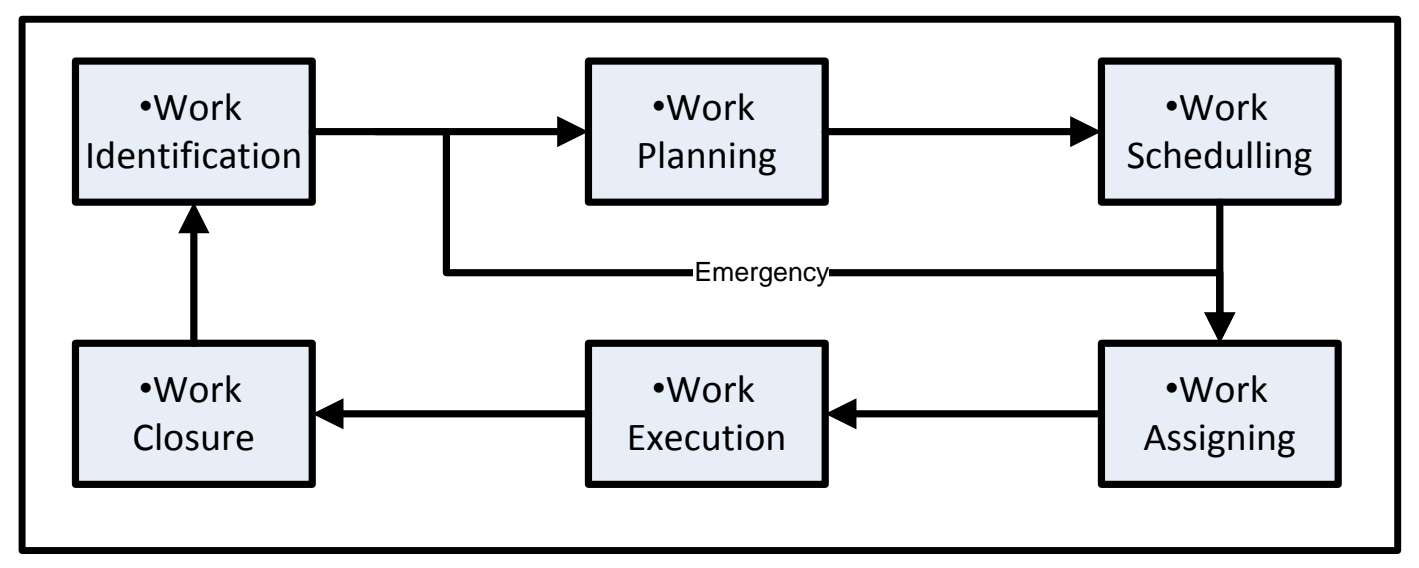

Gambar 5. Diagram Alir Work Management MSD

Peneliti, bekerja sama dengan team dari MOD dan MSD, serta bersama dengan vendor perangkat lunak pihak ketiga, melakukan proyek uji coba dengan memasang suatu perangkat keras dan lunak tambahan pada alat berat yang berfungsi untuk mengirimkan data elektronik secara langsung (real time) dari ECM dan memantau serta menganalisa data-data tersebut. Protokol Uji Coba dibuat untuk mempersiapkan dan mendokumentasikan secara resmi uji coba yang dilakukan. Proyek uji coba tersebut dilakukan pada tahun 2017 selama 3 bulan pada 73 unit Truck dan Digger bernagai merek yaitu Caterpillar, Hitachi dan Komatsu Truck, Hitachi dan Liebher Digger. Beberapa sasaran yang diharapkan dapat dipenuhi dalam dari proyek uji coba tersebut antara lain :

1. Dapat dilakukan pemantauan secara langsung dan terus menerus terhadap data parameter dari ECM

2. Tersedia detail informasi untuk setiap parameter yang bisa ditampilkan seperti nama operator, lokasi, dll

3. Tersedia data history dalam grafik trending untuk mendukung analisa mendalam mengenai kesehatan unit alat berat

4. Dapat menangkap snapshot dan mengambil data-data hisory dari parameter-parameter yang dibutuhkan untuk analisa terkait improvement dan investigasi accident.

Untuk dapat menilai dan mepertimbangkan dengan baik keberhasilan proyek uji coba yang dilakukan, peneliti juga membuat matriks dan scoring perbandingan untuk memperbandingkan kemampuan dari masing-masing perangkat lunak yang sudah terpasang dan digunakan saat ini di masing-masing alat berat sebagai baseline dengan kemampuan perangkat lunak yang diujicobakan. Matriks yang dibuat meliputi detail kemampuan perangkat lunak dalam menampilkan berbagai tipe data beserta level detail yang dibutuhkan dan termasuk juga kevalidan nilai dari data yang disajikan. Beberapa simulasi juga dilakukan untuk meyakinkan bahwa antara data yang disajikan benar-benar sesuai dengan kejadian aktual di lapangan.

Untuk menambah nilai dari perangkat lunak yang sedang diuji coba, juga dilakukan kustomisasi beberapa parameter real time yang dapat dimunculkan tersebut, menjadi beberapa event (fault) baru yang sebelumnya tidak pernah muncul pada perangkat lunak bawaan asli pabrikan namun menjadi issue penting yang seharusnya dapat dipantau lebih dini agar kejadiannya dapat dicegah atau diminimalisisr sekecil mungkin untuk menhindari kerusakan pada komponen alat berat. Event atau fault baru ini berhubungan dengan pengoperasian alat berat yang tidak sesuai dengan panduan yang 
diberikan. Agar dapat lebih optimal menurunkan potensi kerusakan akibat pengoperasian yang salah ini, juga dilakukan set up pada perangkat lunak sehingga dapat mengeluarkan alarm atau peringatan dini dan mengirimkan notofikasi kepada pihak-pihak yang terkait.

Peneliti juga melakukan simulasi perhitungan untuk memperkirakan potensi saving yang dapat dilakukan dengan menerapkan pemasangan perangkat lunak tersebut, dibandingkan dengan kemampuan perangkat lunak tersebut serta biaya dan konsekuensi lain yang akan timbul. Dengan dapat ditampilannya data-data penting secara langsung dan adanya peringatan dini, maka potensi kerusakan dini pada komponen alat berat akan menjadi berkurang, dan bahkan ada peluang untuk memanjangkan umur komponen sampai level tertentu dengan cara memantau data secara lebih ketat.

Selain itu, peneliti juga melakukan benchmarking yaitu study perbandingan dengan mencari alternatif perangkat lunak lain yang mempunyai kemampuan serupa dari berbagai lokasi tambang lain agar mendapatkan informasi yang valid dan objectif sebanyak-banyaknya dari berbagai sumber. Benchmarking dilakukan ke tambang yang berada di Sulawesi yang kebetulan mempunyai alat-alat berat yang hampir setipe dengan di KPC.

\section{HASIL DAN PEMBAHASAN}

Data Electronic yang dapat direkam dan disimpan di media penyimpanan oleh ECM alat berat, pada umumnya terdiri dari beberapa tipe data yaitu :

1. Fault / Event : menampilan catatan ketika ada kejadian suatu parameter melebihi batasan nilai yang diijinkan yang telah di set up di ECM.

2. Trend : menampilkan trending / kecenderungan dari sample data critical parameter yang dilakukan setiap interval waktu tertentu selama beberapa periode waktu tertentu

3. Data Logger : menampilan catatan atau rekaman semua parameter secara detail sampai detik per detik dalam interval beberapa waktu tertentu saja, data logger harus diinisiasi atau diaktifkan terlebih dahulu untuk dapat diambil datanya.

4. Cummulative : menampilkan catatan akumulusi data dari beberapa critical parameter yang penting

5. Snapshot : hampir sama seperti datalogger, menampilkan catatan atau rekaman semua parameter secara detail sampai detik per detik, namun diinisiasi secara otomatis saat terjadi kejadian (event / fault) yang sangat critical. Namun untuk snapshot data yang direkam adalah data mundur kebelakang dan durasinya biasanya lebih pendek daripada datalogger.

6. Histogram : menampilkan catatan akumulusi data dari critical parameter yang penting dalam bentuk diagram batang, biasanya data yang ditampilkan sudah dalam pengelompokan data

7. Payload : menampilkan catatan pencapaian produktifitas alat berat terutama truck dalam suatu periode tertentu.

Tidak semua seperangkat lunak bawaan asli dari pabrikan pembuat alat berat dapat menampilkan semua tipe data tersebut secara lengkap dan detail. Beberapa unit alat berat sudah melakukan perbaikan dengan menyajikan data real time, namun data yang ditansmit hanyalah Fault / Event dan Trend, bukan Parameter Real Time yang dibutuhkan untuk analisa komprehensif. Data Electronic tersebut.

Improvement dilakukan dengan mengubah metode pengiriman data electronic yang semula menggunakan manual download dain dilakukan setiap 250 jam sekali, menjadi via jaringan wifi dan dilakuakan secara real time dan terus menerus 24 jam dalam sehari. 


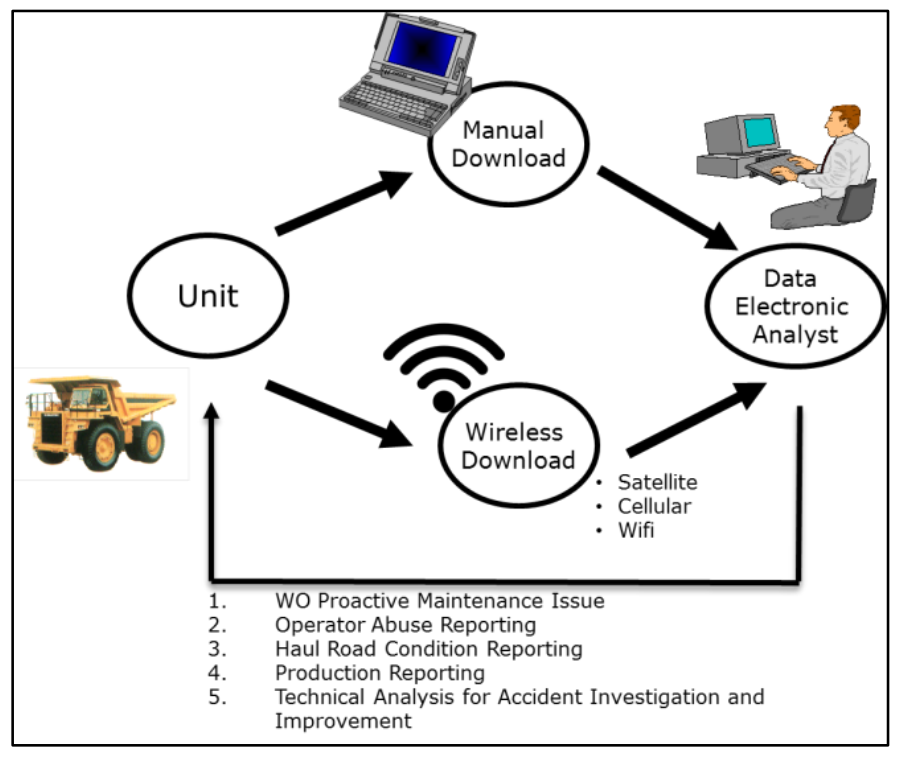

Gambar 6. Diagram Alir Perbandingan Media Pengiriman Data Electronic

Berdasarkan sasaran yang diharapkan untuk dapat dipenuhi oleh perangkat lunak yang diuji coba, maka ruang lingkup dari perangkat lunak telah diprogram untuk dapat melakukan :

1. Real Time Monitoring : menampilkan data kesehatan unit secara real-time

2. Event Handling : menyediakan notikasi / peringatan dini dengan informasi yang detail

3. Trending: membuat dan menganalisa kecenderungan data untuk memperkirakan kerusakan komponen

4. Time Tracking : memberikan notifikasi lengkap ketika unit sedang rusak

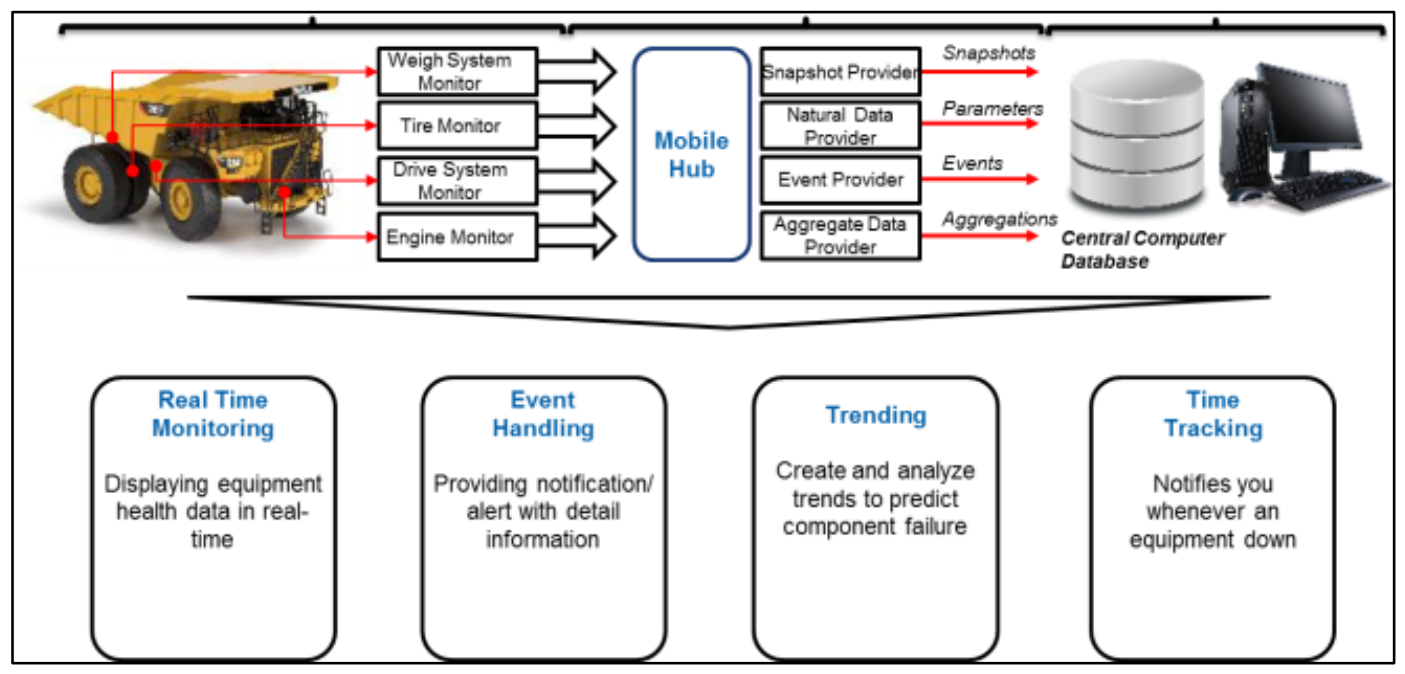

Gambar 7. Diagram Alir Pemetaan Tipe Data Electronic pada Uji Coba Perangkat Lunak di KPC

Dari hasil pemantauan selama 3 bulan, dilakukan penilaian terhadap kemampuan semua jenis perangkat lunak yang sudah terpasang di masing-masing unit alat berat dan dibandingkan dengan perangkat lunak yang baru. 
Tabel 1. Matriks Perbandingan Kondisi dan Kemampuan Perangkat Lunak beberapa Jenis Haul Truck yang terpasang di KPC

\begin{tabular}{|c|c|c|c|c|c|c|c|c|c|c|c|c|c|c|}
\hline \multirow{3}{*}{$\begin{array}{c}\text { Aplikasi } \\
\text { Alat Berat }\end{array}$} & \multirow{3}{*}{ Pabrikan } & \multicolumn{9}{|c|}{ Kebutuhan Analisa Data Electronic } & \multirow{3}{*}{$\begin{array}{l}\text { Data } \\
\text { Akuisi } \\
\text { si }\end{array}$} & \multirow{2}{*}{\multicolumn{2}{|c|}{$\begin{array}{c}\text { Kemudahan Analisa } \\
\text { Data pada Perangkat } \\
\text { Lunak }\end{array}$}} & \multirow{3}{*}{$\begin{array}{l}\text { Total } \\
\text { Score }\end{array}$} \\
\hline & & \multicolumn{4}{|c|}{ Pemantauan Kesehatan Unit } & \multirow{2}{*}{$\begin{array}{c}\text { Pemantauan } \\
\text { Perilaku } \\
\text { Operator }\end{array}$} & \multirow{2}{*}{$\begin{array}{l}\text { Pemanta } \\
\text { uan } \\
\text { Kondisi } \\
\text { Jalan }\end{array}$} & \multirow{2}{*}{$\begin{array}{c}\text { Pemantau } \\
\text { an } \\
\text { Produktifi } \\
\text { tas Alat }\end{array}$} & \multicolumn{2}{|c|}{$\begin{array}{c}\text { Program } \\
\text { Improvement dan } \\
\text { Mendukung } \\
\text { Investigasi }\end{array}$} & & & & \\
\hline & & Trend & $\begin{array}{c}\text { Event / } \\
\text { Fault }\end{array}$ & Histogram & $\begin{array}{c}\text { Cummulat } \\
\text { ive }\end{array}$ & & & & Snapshot & Dataloger & & $\begin{array}{c}\text { Tampilan } \\
\text { Antarmuka }\end{array}$ & $\begin{array}{l}\text { Kecepata } \\
\text { n } \\
\text { Pemroses } \\
\text { an Data } \\
\end{array}$ & \\
\hline Haul Truck & Hitachi & 0 & 1 & 2 & 1 & 2 & 0 & 2 & 1 & 0 & 0 & 1 & 2 & 12 \\
\hline Haul Truck & Komatsu & 2 & 2 & 2 & 2 & 2 & 1 & 2 & 0 & 0 & 1 & 2 & 1 & 17 \\
\hline
\end{tabular}

\section{KESIMPULAN}

Proyek uji coba pemasangan perangkat lunak yang dilakukan di KPC untuk improvement akuisisi data electronic secara real time dan terus menerus, menyediakan notikasi / peringatan dini dengan informasi yang detail, membuat dan menganalisa kecenderungan data untuk memperkirakan kerusakan komponen, dan memberikan notifikasi lengkap ketika unit sedang rusak berhasil dilakukan.

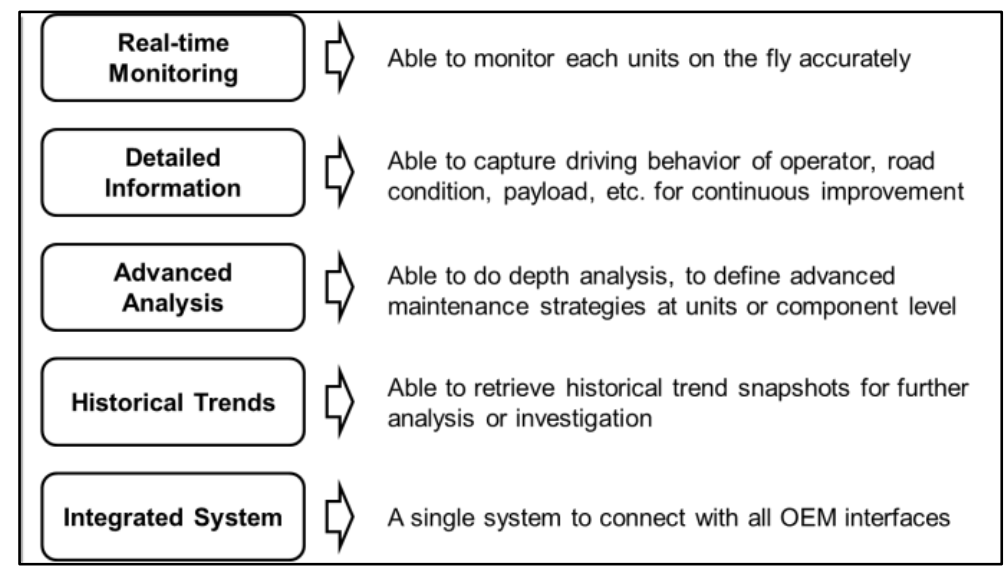

Gambar 8. Check List Presentasi Kesimpulan Proyek Uji Coba Perangkat Lunak di MSD

Data electronic yang telah dapat diakuisisi dan dapat dianalisa secara lebih cepat tersebut membantu team MSD dalam menentukan strategy maintenance predictive sehingga penjadwalan pemeliharaan unit alat berat dapat dilakukan lebih tepat sasaran sesuai kebutuhan, dan dapat dipersiapkan semua sumberdaya baik tenaga mekanik dan supervisinya, ruang di workshop beserta semua peralatan pendukungnya serta spare parts dan juga alokasi costnya. Dengan jadwal yang baik maka durasi pemeliharaan yang dilakukan juga akan lebih pendek sehingga kinerja alat berat dapat terjaga.

Di sisi operation, MOD juga dapat menggunakan data real time parameter tersebut untuk pemantauan produktifitas alat (payload) secara lebih akurat dan detail, serta pemantauan terhadap faktor pendukung operasional yang lain yaitu, perilaku operator yang tidak sesuai dan juga pemantauan kondisi jalan tambang.

Perilaku operator yang tidak sesuai terdiri dari overspeed violation (baik ground speed maupun engine speed), harsh braking atau brake violation (aplikasi pengereman yang tidak sesuai), harsh cornering (aplikasi manuver yang tidak sesuai). 
Jalan tambang merupakan sarana pendukung oeparsional tambang yang juga cukup penting, kondisi jalan tambang yang berupa tanah dan seringkali tidak keras serta setiap saat terpapar hujan dan selalu dilewati oleh haul truck menyebabkan seringkali kondisi jalan tambang sangat buruk dan membutuhkan perbaikan dengan menggunakan alat Grader atau mungkin Dozer.

Perilaku operator yang tidak seusai dan kondisi jalan yang buruk cenderung menyebabkan kerusakan komponen alat berat secara prematur terutama pada ban dan rangka (chasis) serta dapat menyebabkan konsumsi bahan bakar tidak sesuai (boros).

Bahan bakar dan ban adalah biaya konsumsi yang sangat besar dalam pengoperasian tambang, dengan dapat dikontrolnya dua item tsb menjadi efektif dan efisien, serta dengan meningkatnya produkitivitas dan kinerja alat berat, maka keuntungan perusahaan akan meningkat.

\section{DAFTAR PUSTAKA}

Stimik Perbanas Renaissance Center. (2000). Kumpulan Artikel Indrajit, R.E. Manajemen Sistem Informasi dan Teknologi Informasi.. Diperoleh pada 15 Sept 2019. https://ekaanresangsya.it.student.pens.ac.id/files/Manajemen\%20Sistem\%20Informasi.pdf

Jennions, I.K (2011). The P-F Interval Explained. Diperoleh pada 15 Sept 2019. https://www.maintenanceandengineering.com/2018/08/03/the-p-f-interval-explained

Nowakowski Tomasz, TubisSylwia Agnieszka, Wojciechowska Werbińska. (2018). Evolution of Technical Systems Maintenance Approaches - Review and a Case Study. Diperoleh pada 15 Sept 2019.

https://link.springer.com/chapter/10.1007/978-3-319-97490-3_16

PT Kaltim Prima Coal. (2008). Work Management Implementation Policy. Sangata : Internal Document. 